\title{
Effect of Thermal Conditions on Corrosion Behavior of Ductile Cast Iron
}

\author{
Chien-Hung Lin ${ }^{1 *}$, Jia-Ren Lee ${ }^{2}$, Pei-Jing Teng ${ }^{1}$ \\ ${ }^{1}$ Department of Physics, ROC Military Academy, Feng-Shan, Kaohsiung, Taiwan \\ ${ }^{2}$ Department of Physics, National Kaohsiung Normal University, Kaohsiung, Taiwan \\ *E-mail: linhungcma@gmail.com
}

doi: $10.20964 / 2019.11 .19$

Received: 2 July 2019 / Accepted: 21 August 2019 / Published: 7 October 2019

Spherical nodules inhibit crack propagation in ductile cast iron (DCI) and improve its ductility. In this study, we investigated the failure mechanism of DCI under atmospheric exposure and carried out slow strain rate testing (SSRT) to evaluate its mechanical properties. The tensile strengths of the DCI specimens at the operational temperatures of -30 and $100^{\circ} \mathrm{C}$ were 440.2 and $388.8 \mathrm{MPa}$, respectively. The mechanical strength of the DCI specimens decreased with an increase in the operational temperature. Moreover, the corrosion current densities of the DCI specimens in the presence of brine water at 100 and $27{ }^{\circ} \mathrm{C}$ were $3.84 \times 10^{-4}$ and $3.97 \times 10^{-5} \mathrm{~A} / \mathrm{cm}^{2}$, respectively. Under ambient conditions, the corrosion rate of DCI was more than one order of magnitude lower than that under the extreme condition. The DCI specimens exhibited poor mechanical performance in the presence of brine water $(3.5 \mathrm{wt} \% \mathrm{NaCl})$, especially in boiled water because of their stress corrosion cracking. Consequently, the DCI specimens showed partial ductile fracture because of their quasi-cleavage features in the ambient environment and brittle-type cleavage fracture in brine water. The microscopic observations were consistent with the SSRT results. The findings of this study will be helpful in improving the mechanical properties of DCI.

Keyword: ductile cast iron, slow strain rate testing, stress corrosion cracking, ductile

\section{FULL TEXT}

(C) 2019 The Authors. Published by ESG (www.electrochemsci.org). This article is an open access article distributed under the terms and conditions of the Creative Commons Attribution license (http://creativecommons.org/licenses/by/4.0/). 